\title{
SSynthesis
}

International Scientific Conference of IT and Business-Related Research

\section{PREDVIĐANJE KRETANJA TRŽIŠNOG INDEKSA BELEXLINE NA BAZI ARIMA MODELA}

\author{
FORECASTING MARKET INDEX BELEXLINE MOVEMENTS \\ BASED ON ARIMA MODEL \\ Vesna Prorok, Slađana Paunović \\ Ekonomski fakultet Pale, Univerzitet u Istočnom Sarajevu, Republika Srpska
}

\begin{abstract}
Apstrakt:
Cilj rada jeste da se empirijski pokuša predložiti najbolji linearni ARIMA model kojim bi se opisalo i predvidelo buduće kretanje berzanskog indeksa Beogradske berze BELEXline. Izbor najboljeg modela podrazumeva sprovođenje faza identifikovanja, procene i provere validnosti modela. Identifikovanje modela vrši se na bazi posmatranja autokorelacione funckije i funcije parcijalne autokorelacije vremenske serije onog nivoa diferencije pri kome je uslov stacionarnosti serije ispunjen. Parametri više identifikovanih modela ocenjuju se metodom najmanjih kvadrata, te da bi se osigurala nepristrasnost rezultata, potrebno je izvišiti testiranje njihovih reziduala. Modeli koji bi se mogli uzeti u razmatranje su oni čiji reziduali poseduju normalan raspored i ne ukazuju na prisustvo autokorelacije. Između nekoliko predloženih modela koji ispunjavaju navedene uslove, relativno najbolji biće onaj sa minimalnim vrednostima informacionih kriterijuma AIC i SIC, kao iminimalnim vrednostima pokazatelja kvaliteta prognoze. Sledeći navedenu proceduru, empirijskom analizom serije kvartalnih podataka BELEXlina indeksa u periodu od decembra 2004. do marta 2015. godine, predložena su dva modela za koje se pretpostavlja da mogu obezbediti dobre rezultate prognoziranja budućeg kretanja indeksa.
\end{abstract}

\section{Ključne reči:}

BELEXline, ARIMA model, stacionarnost, ACF, PACF.

\section{UVOD}

Značajne promene u međunarodnom finansijskom sistemu kao što je pojava novih tržišta kapitala, ukidanje kapitalnih barijera i sloboda kretanja kapitala, proširile su mogućnosti investiranja i učinile to da, u proteklom periodu, tržišta u razvoju i slabo razvijena tržišta postanu predmet istraživanja velikog broja finasijskih analitičara. To iz razloga što takva istraživanja, nesumnjivo, pružaju investitorima odgovarajuće informacije na osnovu kojih donose svoje investicionu odluke, u nastojanju da izvrše efikasnu alokaciju sredstava i obezbijede što bolju diversifikaciju svojih investicionih portfolija.

Berzansko tržište, kao jedan od osnovnih elemenata tržišta kapitala, u najvećoj mjeri doprinosi ekonomskom razvoju jedne zemlje. Međutim, svetska ekonomska i finansijska kriza koja je početkom 2008. godine uzdrmala sva svetska tržišta kapitala dovela je u pitanje mogućnost održavanja stabilnosti i najvećih nacionalnih ekonomija. Nedostatak interesa za investiranjem od strane investitora poslednjih godina, rezultat je ostvarivanja velikih gubitaka na tržištima kapitala, nastalih kao posledica

\section{Abstract:}

The aim of this paper is to attempt to empirically propose the most appropriate linear ARIMA model for describing and forecasting future movements of the Belgrade Stock Exchange index, BELEXline. Model selection involves implementation of three phases: identification, estimation and verification of the validity of the model. Model identification is performed on the basis of both auto-correlation (ACF) and partial auto-correlation function (PACF) of time series of the degree of difference in which the condition of stationarity is met. The parameters of several identified models are estimated using OLS method, and therefore, in order to ensure unbiased results, the residuals of the proposed models should be examined. Models that could be taken into consideration are those whose residuals have a normal distribution and do not indicate the presence of auto-correlation. Among several proposed models that meet the aforementioned requirements, the most suitable would be the one with the minimum value of information criteria AIC and SIC, and minimum values of quality indicators of forecasting. Based on the above-given procedure, two models have been proposed by means of the empirical analysis of a series of quarterly data Belexline during the period from December 2013 to March 2015, which are expected to provide favourable results concerning forecasting future movements of the index.

\section{Key words:}

BELEXline, ARIMA model, stationarity, ACF, PACF.

nepredviđenih fluktuacija. To se naročito osetilo na tržištima kapitala zemalja u tranziciji, koja su bila najviše izložena dramatičnim fluktuacijama u periodu posle krize. Stoga je opravdana činjenica da su tehnike predviđanja kretanja cena na tržištima kapitala postale jedna od najvažnijih tema u okviru finansijske literature. Tehničke analize predviđanja bazirane na korišćenju istorijskih podataka zasigurno su zasenile i u drugi plan stavile tradicionalnu fundamentalnu analizu kretanja cena na tržištu koja se isključivo oslanjala na intuitivnu spoznaju internih i eksternih faktora koji utiču na poslovanje kompanije. Ukoliko bi postojala mogućnost da se formira odgovarajući model koji će predvideti kretanja na berzanskim tržištima zemalja u razvoju, to bi se, nesumnjivo, pozitivno odrazilo na privlačenje većeg broja investitora i na održavanje stabilnosti nacionalne ekonomije zemlje.

Cilj rada je da se pruži doprinos u pogledu formiranja modela kojim bi se opisalo i predvidelo kretanje tržišnog indeksa Beogradske berze BELEXline. Analiza će se zasnivati na primeni ARIMA modela uz korišćenje kvartalnih podatka o kretanju berzanskog indeksa u periodu od decembra 2004. do marta 2015. godine. 

faze:

Proces izbora predloženog ARIMA modela odvija se u tri

1. identifikacija modela,

2. ocjena modela $\mathrm{i}$

3. predviđanje.

Faza identifikacije obuhvata pronalaženje nivoa stacionarnosti stvarne ili transformisane serije podataka, te određivanje potencijalnog broja lagova autorogresionog modela i modela pokretnih sredina na bazi autokorelacione funkcije (ACF) i funkcije parcijalne autokorelacije (PACF). Vrednosti parametara potencijalnih modela se ocenjuju metodom najmanjih kvadrata, a najniža vrednost kriterijuma AIC i SIC će ukazati na to koji od predloženih modela je relativno najbolji. U narednoj fazi utvrđuje se validnost modela testiranjem serije njegovih reziduala, koji moraju zadovoljiti uslove normalnog rasporeda i nepostojanje autokorelacije. U konačnom, izabrani model koji ispunjava sve navedene uslove može se dalje koristiti za predviđanje budućih kretanja tržišnog indeksa BELEXline.

\section{PREGLED LITERATURE}

Za razliku od regresionih modela u kojima se jedna varijabla objašnjava kretanjem jedne ili više drugih varijabli, ARIMA modeli omogućavaju da se kretanje varijable objasni vrednostima same varijable i stohastičkim greškama iz prethodnih perioda (Kalu, 2010). ARIMA modeli ne podrazumevaju formiranje simultane jednačine već analiziraju verovatnoće ili stohastičke karakteristike vremenske serije, zasnovane na njenim istorijskim podacima.

U nastavku ćemo se kratko osvrnuti na rezultate istraživanja o predviđanju vrednosti tržišnih indeksa zemalja u razvoju sprovedenih u poslednjoj deceniji, primjenom ARIMA ili drugih alternativnih modela koji su se u određenim analizama pokazali efikasnijim.

Emenike Kalu (2010) je na bazi mesečnih podataka u periodu od 1985. do 2008. godine predložio ARIMA $(1,1,1)$ model kojim bi se predvidelo kretanje berzanskog indeksa na tržištu Nigerije. Međutim, nepredviđene fluktuacije na svetskim finansijskim tržištima, uzrokovane svetskom ekonomskom i finansijskom krizom, dovele su do toga da se takav model u kratkom vremenu, pokaže kao neuspešan.

Sličnu metodologiju koristili su Rotela Junior et al. (2014) prilikom formiranja modela za predviđanje kretanja berzanskog indeksa Brazilske berze (Ibovespa) koristići mesečne podatke iz perioda od januara 1995. do januara 2013. godine. Od četiri predviđena modela, kao najbolji pokazao se AR1 model, što su potvrdili i rezultati statistike koeficijenata AR1 modela i $\chi^{2}$ statistike. Izbor modela izvršen je primenom MAPE kriterijuma čija je vrednost za AR1 model iznosila 0,052\%, što je bilo manje u poređenju sa vrednostima MAPE kriterijuma alternativnih modela.

Simons i Laryen (2005) su testirali održivost hipoteze slabe forme efikasnosti na četiri afrička tržišta (Južna Afrika, Gana, Mauricijus i Egipat) na osnovu sedmičnih i mesečnih podataka u periodu od 1990. do 2003. godine. Primjenom neparametarskih i parametarskih testova došli su do zaključka da je hipoteza slabe forme efikasnosti ispunjena samo na tržištu Južne Afrike, dok su se za ostala tržišta Box-Jeniks metodologijom formirali ARIMA modeli (Egipat ARIMA $(1,0,1)$, Gana ARIMA $(1,0,2)$ i Mauricijus ARIMA $(2,0,1))$ za predviđanje budućih kretanja njihovih tržišnih indeksa. Sama činjenica da se takvi modeli mogu formirati je, prema hipotezi slučajnog hoda, već dovoljan pokazatelj neefikasnosti tržišta. Ovakve analize u finansijskoj literaturi nisu bile rijetke. Još jedan od dokaza neispunjenosti hipoteza slabe forme efikasnosti, na sličan način, pružili su Rahman i Hossain u radu Dhaka Stock Exchange: Weak-Forma Efficiency for both Traditional Company and Islamic Company. Za potrebe analize korišteni su dnevni podaci berzanskog indeksa u Daki u periodu od 1. januara 1994. do 30. marta 2005. godine. Rezultati su odbacili nultu hipotezu slučajnog hoda, te su se na bazi AIC kriterijuma odabira optimalnog broja lagova, koeficijenta determinacije i autokorelacione funckije predložila dva ARIMA modela (ARIMA $(3,0,2)$ i ARIMA $(1,0,1))$ kojima bi se opisalo kratkoročno kretanje indeksa berze u Daki. Oba modela bila su odgovarajuća, sa stitistički značajnim koeficijentima pri nivou značajnosti od $1 \%$.

Mnogi autori, kao osnovni nedostatak ARIMA modela, ističu nemogućnost da obuhvati nelinearne komponente prilikom predviđanja. Iz tog razloga danas je sve veći broj modela zasnovanih na kombinaciji linearnih i nelinearnih komponenti, koje doprinose poboljšanju performansi predviđanja.

\section{METODOLOGIJA I ANALIZA}

\subsection{ARIMA MODEL}

ARIMA modeli su, u finansijskoj literaturi, najčešće korišteni linearni modeli analize i predviđanja vremenskih serija, s obzirom na to da, zbog svoje fleksibilnosti, mogu ujedno predstaviti komponente tri različita modela:

1. čistog autoregresionog modela (AR),

2. čistog modela pokretnih sredina (MA) i

3. kombinciju AR i MA modela, tj. ARMA modela.

ARIMA modeli obilježavaju se sa $\operatorname{ARIMA}(p, d, q)$, gdje $p$ i $q$ predstavljaju broj lagova AR i MA modal, respektivno, uključenih u ARIMA model, dok $d$ ukazuje na nivo integrisanosti ili stacionarnosti posmatrane vremenske serije. Buduća vrijednost varijable prema ARIMA modelu predstavlja linearnu funkciju vrijednosti varijable i standardnih grešaka iz prethodnih perioda čija dinamika je opisana sljedećim izrazom:

$$
y_{t}=\phi_{0}+\sum_{p=1}^{P} \phi_{p} y_{t-p}+\sum_{q=1}^{Q} \theta_{q} \varepsilon_{t-q}+\varepsilon_{t}
$$

gdje je $\varepsilon_{t}$ proces bijelog šuma sa karakteristikom $E_{t-1}\left[\varepsilon_{t}\right]=0$.

Parametri $\phi_{i}(i=1,2,3, \ldots, p)$ i $\theta_{j}(j=0,1,2 \ldots, q)$ su parametri lagova AR i MA modela. Proces izabora potencijalnog broja modela zasniva se na Box-Jenkins metodologiji, koju čine faze identifikacije, ocjene i provjere modela.

\subsection{IDENTIFIKACIJA MODELA BELEXLINE INDEKSA}

BELEXline je opšti indeks Beogradske berze u čiju strukturu, trenutno, ulaze akcije 54 kompanije. To su akcije kojima se trguje na Beogradskoj berzi i koje su ispunile sve kriterijume za ulazak u indeksnu korpu.

Empirijska analiza formiranja odgovorajućeg modela predviđanja kretanja tržišnog indeksa BELEXline zasnivaće se na kvartalnim istorijskim podacima indeksa u periodu od decembra 2004. do marta 2015. godine. Na grafikonu 1. i 2. predstavljena je stvarna i logaritamski transformisana vremenska serija podataka koja će biti predmet analize pri formiranju ARIMA modela. 

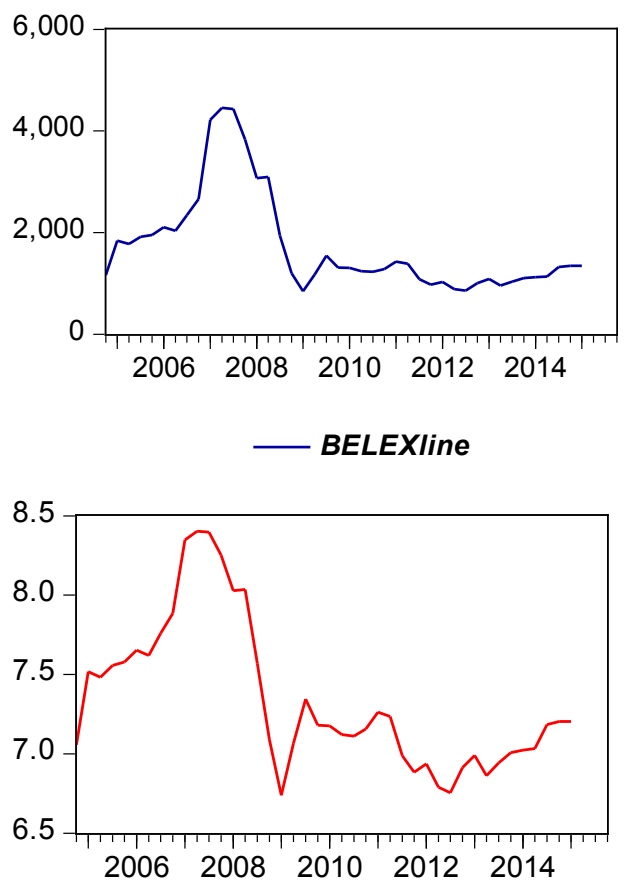

$\log (B E L E X I i n e)$

Grafik 1-2. Prikaz stvarne i logaritamski transformisane serije podataka BELEXline indeksa

Za potrebe analize neophodno je utvditi stacionarnost posmatranih vremenskih serija, jer svaki model zasnovan na stacionarnoj seriji podataka je sam po sebi već stacionaran i predstavlja dobru osnovu za buduća predviđanja. Rezultati proširenog Diki-Fulerovog testa, prikazani u tabeli 1 , ukazali su na postojanje jediničnog korjena za podatke na nivou, dok je uslov stacionarnosti bio ispunjen za diferencirane podatke kako stvarne, tako i logaritamski transformisane serije podataka BELEXline indeksa.
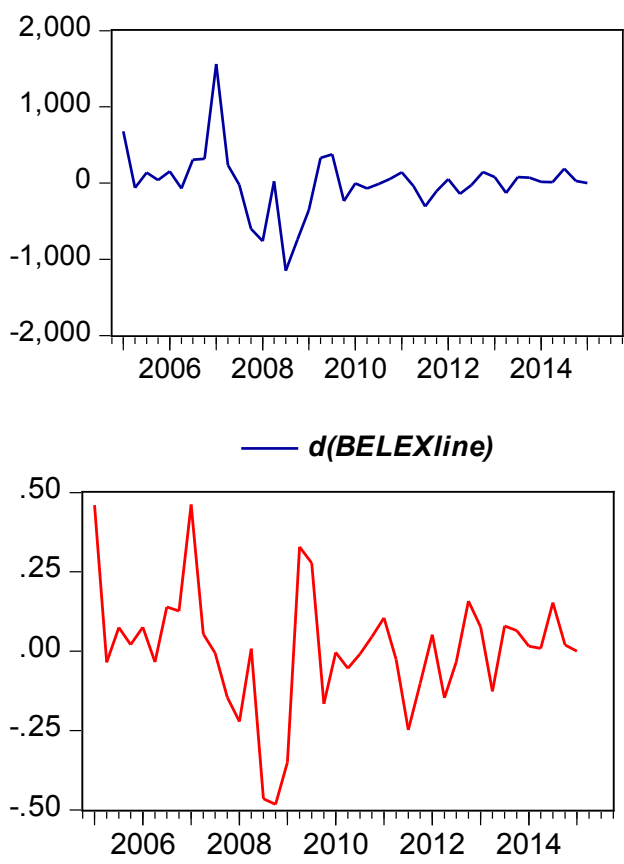

$d(\log (B E L E X I i n e))$

Grafik 3-4. Prikaz diferencirane stvarne i logaritamski transformisane serije podataka BELEXline indeksa

\begin{tabular}{|c|c|c|}
\hline Varijable & ADF & $\mathrm{I}(\mathrm{d})$ \\
\hline BELEXline & $-1,864694$ & $\mathrm{I}(1)$ \\
\hline $\mathrm{d}($ BELEXline $)$ & $-3,123049^{*}$ & $\mathrm{I}(0)$ \\
\hline $\log ($ BELEXline $)$ & $-1,766608$ & $\mathrm{I}(1)$ \\
\hline $\mathrm{d}(\log ($ BELEXline $))$ & $-4,928887^{*}$ & $\mathrm{I}(0)$ \\
\hline
\end{tabular}

Tabela 2. Rezultati ADF testa jediničnog korjena stvarnih i logaritamski transformisanih vremenskih serija za podatke na nivou i za diferenciranu seriju podataka

Kada smo utvrdili nivo stacionarnosti, pristupamo identifikaciji modela na bazi posmatranja autukorelacione funkcije i funkcije parcijalne autokorelacije. Autokorelaciona funkcija daće nam informaciju o potencijalnom broju lagova modela pokretnih sredina, dok će nam funkcija parcijalne autokorelacije poslužiti za odabir broja lagova autoregresionog modela, uključenih u ARIMA model.

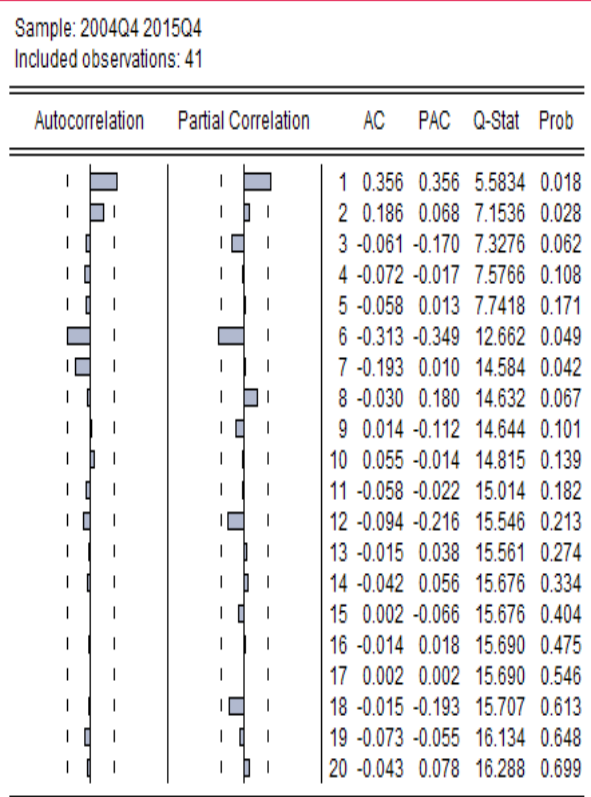

Prikaz 1. ADF i PACF diferencirane serije BELEXline indeka

\begin{tabular}{|c|c|c|c|c|c|c|}
\hline Autocorr & rrelation & Partial Correlation & $A C$ & PAC & Q-Stat & Prob \\
\hline & 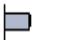 & । 口 & 10.298 & 0.298 & 3.9047 & 0.048 \\
\hline 1 & 1 & 101 & $2-0.003$ & -0.100 & 3.9050 & 0.142 \\
\hline 1 & 1 & 11 & $3-0.067$ & -0.040 & 4.1136 & 0.249 \\
\hline 1 & b 1 & 1 & 40.055 & 0.098 & 4.2568 & 0.372 \\
\hline 1 & 1 & 101 & $\begin{array}{ll}5 & -0.047\end{array}$ & -0.112 & 4.3669 & 0.498 \\
\hline 10 & 1 & 101 & $6-0.136$ & -0.099 & 5.2989 & 0.506 \\
\hline 10 & 1 & I & $7-0.076$ & 0.009 & 5.5953 & 0.588 \\
\hline 10 & 1 & 101 & $8-0.112$ & -0.133 & 6.2633 & 0.618 \\
\hline 10 & 1 & 11 & $\begin{array}{lll}9 & -0.087\end{array}$ & -0.030 & 6.6772 & 0.671 \\
\hline & b & । & $\begin{array}{ll}10 & 0.094\end{array}$ & 0.162 & 7.1808 & 0.708 \\
\hline 1 & 1 & 101 & $\begin{array}{ll}11 & 0.032\end{array}$ & -0.097 & 7.2420 & 0.779 \\
\hline 10 & 1 & 101 & $\begin{array}{ll}12 & -0.107\end{array}$ & -0.116 & 7.9417 & 0.790 \\
\hline 1 & 1 & 1 & $\begin{array}{ll}13 & 0.012\end{array}$ & 0.137 & 7.9503 & 0.847 \\
\hline 1 & 1 & 101 & $\begin{array}{ll}14 & 0.017\end{array}$ & -0.116 & 7.9702 & 0.891 \\
\hline 1 & 1 & 101 & $15-0.065$ & -0.101 & 8.2601 & 0.913 \\
\hline 1 & 1 & 111 & $16-0.143$ & -0.016 & 9.6949 & 0.882 \\
\hline 1 & b 1 & 101 & $\begin{array}{ll}17 & 0.072\end{array}$ & 0.099 & 10.075 & 0.900 \\
\hline 1 & b 1 & 101 & 180.046 & -0.068 & 10.240 & 0.924 \\
\hline 10 & 1 & 101 & $19-0.136$ & -0.128 & 11.729 & 0.897 \\
\hline 10 & 1 & 11 & $20 \begin{array}{rr}20.062\end{array}$ & 0.033 & 12.057 & 0.914 \\
\hline
\end{tabular}

Prikaz 2. ADF i PACF diferencirane serije logaritamski transformisanog BELEXline indeksa 
Na bazi posmatranja korelograma autokorelacije i parcijalne autokorelacije diferenciranih podataka stvarne i logaritamski transformisane vremenske serije BELEXline indeksa, predložićemo nekoliko ARIMA modela za predviđanje njegovog budućeg kretanja. Predloženi modeli prikazani su u tabelama 3 i 4.

\begin{tabular}{|c|c|c|c|c|c|}
\hline & Model 1 & Model 2 & Model 3 & Model 4 & Model 5 \\
\hline $\operatorname{AR}(1)$ & $\sqrt{ }$ & & & $\sqrt{ }$ & $\sqrt{ }$ \\
\hline $\operatorname{AR}(2)$ & & & & $\sqrt{ }$ & \\
\hline $\operatorname{MA}(1)$ & & $\sqrt{ }$ & $\sqrt{ }$ & $\sqrt{ }$ & $\sqrt{ }$ \\
\hline $\operatorname{MA}(2)$ & & & $\sqrt{ }$ & & $\sqrt{ }$ \\
\hline
\end{tabular}

Tabela 3. Predloženi modeli na bazi diferencirane stvarne serije podataka BELEXline indeksa

\begin{tabular}{|c|c|c|}
\hline & Model 1 & Model 2 \\
\hline $\operatorname{AR}(1)$ & $\sqrt{ }$ & \\
\hline $\operatorname{MA}(1)$ & & $\sqrt{ }$ \\
\hline
\end{tabular}

Tabela 4. Predloženi modeli na bazi diferencirane logaritamski transformisane serije podataka BELEXline indeksa

U nastavku ćemo ocijeniti vrijednosti parametara identifikovanih modela i izvršiti provjeru njihove validnosti testiranjem serije reziduala. Vrijednosti ocijenjenih parameta se mogu smatrati nepristrasnim samo u slučaju da se radi o modelima čiji reziduali posjeduju normalni raspored, te ispunjavaju uslove homoskedastičnosti i nepostojanja autokorelacije.

\subsection{OCJENA PARAMETARA I PROVJERA VALIDNOSTI PREDLOŽENIH MODELA}

U tabeli 5. i 6. prikazani su rezultati ocijenjenih modela primjenom metoda najmanjih kvadrata. Koeficijenti parametara svih modela su statistički značajni, što je pokazatelj da su predloženi modeli potencijalno odgovarajući i da se mogu koristiti za buduća predviđanja, ali samo pod pretpostavkom da reziduali ispunjavaju već navedene uslove. To bi značilo da se samo uz dodatno testiranje reziduala može zaključiti da li su ocjene parametara predloženih modela pristrasne ili ne. Ako se pokaže

\begin{tabular}{|c|c|c|c|c|c|}
\hline & Model 1 & Model 2 & Model 3 & Model 4 & Model 5 \\
\hline \multirow{4}{*}{ AR(1) } & 0.35549 & & & -0.486235 & -0.347711 \\
& t-statistika & & & t-statistika & t-statistika \\
& 2.475034 & & & -2.870485 & -2.233812 \\
& vjerovatnoća & & & vjerovatnoća & vjerovatnoća \\
& 0.0178 & & & 0.0068 & 0.0316 \\
\hline & & & & 0.274201 & \\
AR(2) & & & & t-statistika & \\
& & & & 2.934643 & \\
& & & & vjerovatnoća & \\
& & & & 0.0058 & \\
& & 0.312437 & 0.639199 & 1.311942 & 0.880173 \\
MA(1) & & t-statistika & t-statistika & t-statistika & t-statistika \\
& & 2.116816 & 5.311101 & 8.311197 & 14.51299 \\
& & vjerovatnoća & vjerovatnoća & vjerovatnoća & vjerovatnoća \\
& & 0.0405 & 0.0000 & 0.0000 & 0.0000 \\
\hline & & & 0.657868 & & 0.940388 \\
& & & t-statistika & & t-statistika \\
MA(2) & & & 5.358453 & & 24.38898 \\
& & & vjerovatnoća & & vjerovatnoća \\
& & & 0.0000 & & 0.0000 \\
\hline
\end{tabular}

Tabela 5. Ocijenjeni parametri predloženih modela na bazi diferencirane stvarne serije podataka BELEXline indeksa da su ocjene parametara pristrasne, takav model će biti isključen iz dalje analize, jer je jasno da neće obezbijediti dobro procjene budućih kretanja varijable.

\begin{tabular}{|c|c|c|}
\hline & Model 1 & Model 2 \\
\hline \multirow{4}{*}{ AR(1) } & 0.140819 & \\
& t-statistika & \\
& 2.107780 & \\
& vjerovatnoća & \\
& 0.0415 & \\
\hline \multirow{3}{*}{ MA(1) } & & 0.430329 \\
& & t-statistika \\
& & 3.230849 \\
& & vjerovatnoća \\
& & 0.0025 \\
\hline
\end{tabular}

Tabela 6. Ocijenjeni parametri predloženih modela na bazi diferencirane logaritamski transformisane serije podataka BELEXline indeksa

Primenom Jarque Bera testa normalnosti utvrđeno je da Modeli 1, 2, 3 i 4 iz tabele 5. ne ispunjavaju uslov normalnosti reziduala, te kao takvi ne mogu biti osnova za dalje predviđanje. Model 5 iz tabele 5. i modeli 1 i 2 iz tabele 6. zadovoljavaju sve pretpostavke koje obezbeđuju efikasne i nepristrasne ocene parametara, tj. njihovi reziduali poseduju normalan raspored, te ne pokazuju prisustvo autokorelacije i heteroskedastičnosti. U nastavku ćemo izvršiti predviđanje kretanja BELEXine na bazi modela 5 iz tabele 5 , dok ćemo od dva predložena modela iz tabele 6. izabrati onaj sa manjom vrednošću informaiconih kriterijuma AIC i SIC kretijuma, kao i manjim vrednostima pokazatelja preciznosti prognoze.

\section{PREDVIĐANJE}

Predloženim ARIMA modelima mogu se oceniti vrednosti za posmatrani period, te predvideti buduće vrednosti indeksa BELEXline. Ocenjene vrednosti za posmatrani period mogu poslužiti kao potvrda adekvatnosti formiranog modela, dok predviđene vrednosti za naredne periode mogu predstavljati osnovu za donošenje investicionih odluka. U tabeli 7. prikazane su vrednosti AIC i SIC kriterijuma, kao i pokazatelji preciznosti predviđanja koji su izračunati za poslednjih 8 kvartala raspoloživog uzorka. Prema svim pokazateljima, kao bolji od dva predložena modela iz tabele 6 , pokazao se model 1 . 


\begin{tabular}{|l|c|c|}
\hline & Model 1 & Model 2 \\
\hline AIC & $-0,633006$ & $-0,547199$ \\
\hline SIC & $-0,590784$ & $-0,505405$ \\
\hline $\begin{array}{l}\text { Korjen srednje kvadratne } \\
\text { greške prognoze }\end{array}$ & 96,24596 & 97,25101 \\
\hline Srednja apsolutna greška & 68,58890 & 71,23850 \\
\hline $\begin{array}{l}\text { Srednja apsolutna } \\
\text { procentualna greška prognoze }\end{array}$ & 6,140396 & 6,262596 \\
\hline
\end{tabular}

Tabela 7. Vrednosti informacionih kriterijuma i pokazatelja preciznosti prognoze za dva predložena modela na bazi diferencirane logaritamski transformisane vremenske serije

Na grafikonima 5. i 6. prikazano je predviđeno kretanje BELEXline indeksa za period do kraja prvog kvartala 2016. godine, na bazi modela 5 iz tabele 5 . i na bazi modela 1 iz tabele 6 , s obzirom na to da je model 1 za difereniranu logaritamski transofrmisanu seriju podataka prema svim kriterijumima bolji.

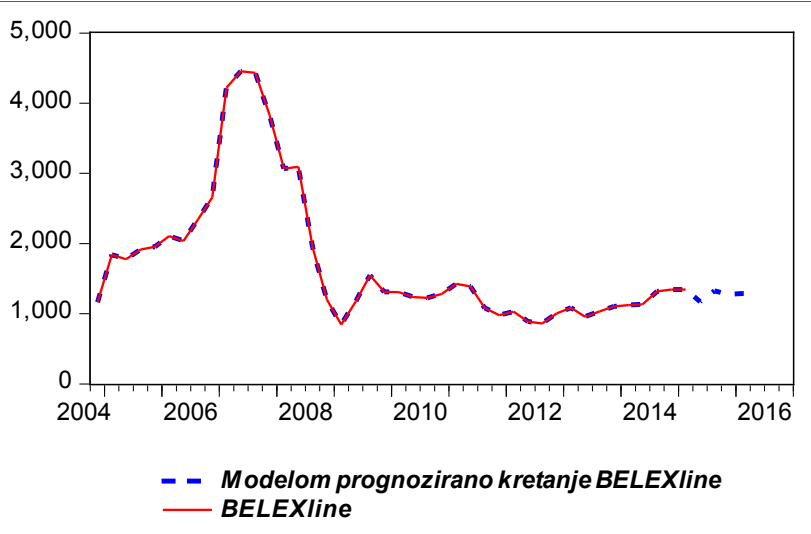

Grafik 5. Prikaz stvarnih i prognoziranih vrednosti BELEXline indeksa na bazi modela 5

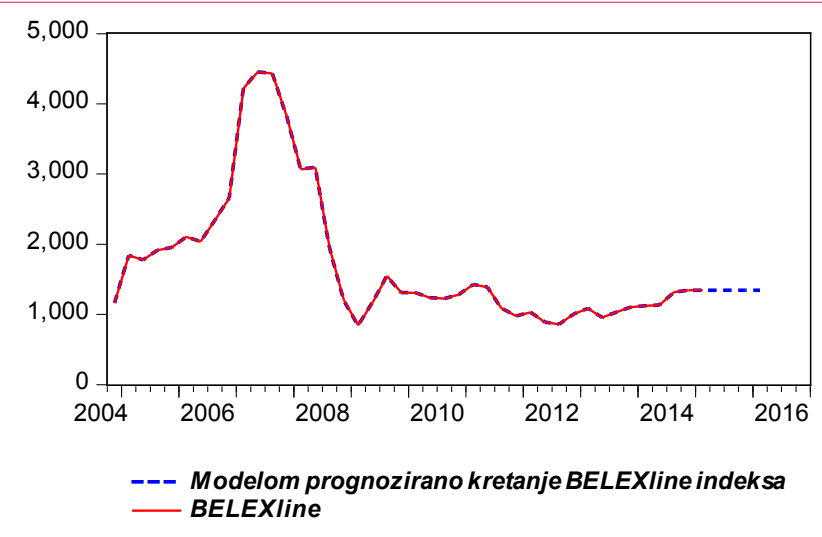

Grafik 6. Prikaz stvarnih i prognoziranih vrednosti BELEXline indeksa na bazi modela 1

\section{ZAKLJUČAK}

U radu je analizirana mogućnost izbora odgovarajućeg ARIMA modela za predviđanje kretanja BELEXline indeksa Beogradske berze na bazi kvartalnih podataka, koji će biti dobra osnova za kratkoročno predviđanje njegovog kretanja.
Identikovan je okvir za ARIMA modeliranje koji obuhvata sledeće korake: identifikacija modela, ocena i verifikacija modela i predviđanje. Najbolji model je izabran upotrebom informacionih kriterijuma AIC i SIC, kao i upotrebom pokazatelja kvaliteta prognoze. Testiranjem serije reziduala modela utvrđeno je da izabrani model ispunjava uslove normalnog rasporeda i nepostojanje autokorelacije i heteroskedstičnosti, te je pogodan za kratkoročno predviđanje budućih kretanja tržišnog indeksa BELEXline.

Naravno, predviđanje kretanja tržišnih indeksa zemalja u razvoju, mnogo je teži posao s obzirom na to da je tehnička analiza namenjena razvijenim i efikasnim tržištima kapitala. Ekonomski ciklusi zemalja u razvoju su mnogo volatilniji i pod uticajem su inostranih priliva kapitala, što značajno umanjuje prediktivnu sposobnost modela.

\section{LITERATURA}

Abdullah, L. (2012). ARIMA Model for Gold Bullion Coin Selling Prices Forecasting. International Journal of Advances in Applied Sciences(IJAAS), 1(4), 153-158.

Afego, P. (2012). Weak Form Efficiency of the Nigerian Stock Market: An Empirical Analysis (1984 - 2009). International Journal of Economics and Financial Issue, 2(3), 340-347.

Campbell, J. Y., Lo, A. W., \& MacKinlay, A. C. (1997). The econometrics of financial markets. Princeton, N.J: Princeton University Press.

Dougherty, C. (2007). Introduction to econometrics. New York: Oxford University Press.

Gourieroux, C., \& Jasiak, J. (2001). Financial econometrics: Problems, models, and methods. Princeton, N.J: Princeton University Press.

Harris, E., Abdul-Aziz, A.R., \& Avuglah, R.K. (2012). Modeling annual Coffee production in Ghana using ARIMA time series Model. International Journal of Business and Social Research, 2(7), 175-186.

Kalu, Emenike O. (2010). Forecasting Nigerian Stock Exchange Returns: Evidence from Autoregressive Integrated Moving Average (ARIMA) Model. Social Science Research Network. Preuzeto 3. marta 2015. sa http://ssrn.com/abstract $=1633006$

Maddala, G.S. (1992). Introduction to Econometrics. New York: Macmillan Publishing Company.

Rahman, S., \& Hossain, F. (2006). Weak-form Efficiency: Testimony of Dhaka Stock Exchange. Journal of Business Research, 8, 1-12.

Rotela Junior, P., Riera Salomon, F.L., \& Oliviera Pampplona, E. (2014). ARIMA: An Applied Time Series Forecasting Model for the Bovespa Stock Index. Applied Mathematics, 5(21), 3383-3391. DOI: 10.4236/am.2014.521315

Simons, D.N., \& Laryea, S. (2005). Testing the Efficiency of African Markets. Social Science Research Network. Preuzeto 3. marta 2015. sa http://economics.ca/2004/papers/0056.pdf

Terrell, D., \& Fomby, T.B. (2006). Econometric analysis of financial and economic time series. Amsterdam: Elsevier. 